Glob Environ Change. 2014 September 1; 28: 182-191. doi:10.1016/j.gloenvcha.2014.07.001.

\title{
Measuring the Environmental Dimensions of Human Migration: The Demographer's Toolkit
}

\author{
Elizabeth Fussell, \\ Population Studies and Training Center, Brown University, Box 1836, 68 Waterman St., \\ Providence, RI 02912, USA
}

Lori M. Hunter, and

Institute of Behavioral Science, CU Population Center, Department of Sociology, University of Colorado Boulder, Boulder, Colorado, USA

Clark L. Gray

Department of Geography, University of North Carolina, Chapel Hill, North Carolina, USA

Elizabeth Fussell: Elizabeth_Fussell@brown.edu

\begin{abstract}
In recent years, the empirical literature linking environmental factors and human migration has grown rapidly and gained increasing visibility among scholars and the policy community. Still, this body of research uses a wide range of methodological approaches for assessing environmentmigration relationships. Without comparable data and measures across a range of contexts, it is impossible to make generalizations that would facilitate the development of future migration scenarios. Demographic researchers have a large methodological toolkit for measuring migration as well as modeling its drivers. This toolkit includes population censuses, household surveys, survival analysis and multi-level modeling. This paper's purpose is to introduce climate change researchers to demographic data and methods and to review exemplary studies of the environmental dimensions of human migration. Our intention is to foster interdisciplinary understanding and scholarship, and to promote high quality research on environment and migration that will lead toward broader knowledge of this association.
\end{abstract}

\section{Keywords}

Migration; Environment; Demography; Climate change; Data; Methods

(C) 2014 Elsevier Ltd. All rights reserved.

Correspondence to: Elizabeth Fussell, Elizabeth_Fussell@brown.edu.

The content is solely the responsibility of the authors and does not necessarily represent the official views of CEP, NIH, or NICHD.

Publisher's Disclaimer: This is a PDF file of an unedited manuscript that has been accepted for publication. As a service to our customers we are providing this early version of the manuscript. The manuscript will undergo copyediting, typesetting, and review of the resulting proof before it is published in its final citable form. Please note that during the production process errors may be discovered which could affect the content, and all legal disclaimers that apply to the journal pertain. 


\section{Introduction}

Climate scientists project that increases in average global temperature will produce sealevel rise and greater weather variability, which could be linked to droughts in some regions, intensified precipitation in others, and more intense and frequent extreme coastal events (Intergovernmental Panel on Climate Change 2007). In turn, these projections have generated growing interest in the implications of climate change for human systems, including migration systems (see Black, Arnell, and Dercon (eds.) 2011, special issue of Global Environmental Change on Migration and Global Environmental Change - Review of Drivers of Migration). Drawing on the findings of qualitative research and case studies of migration decision-making, most scholars in the field reject the deterministic view that directly links climate change to mass migration. Instead, they recognize that the linkages are complex and operate through social, political, economic, and demographic drivers, with migration being just one of many possible adaptations to environmental change (Black, Adger, Arnell, Dercon, Geddes, and Thomas 2011; Jäger, Frühmann, Grünberger, and Vag 2009; McLeman and Smit 2006; McLeman 2014; Piguet, Pécoud, and De Guchteneire 2011). As of yet, however, there are too few studies investigating these complex linkages to make generalizations about the extent to which environmental factors directly or indirectly shape human migration patterns (Jäger, Frühmann, Grünberger, and Vag 2009; Kniveton, Schmidt-Verkerk, Smith, and Black 2008: 57; McLeman and Hunter 2010; Piguet 2010; Warner 2011).

Leading scholars in this field note that advances in the quality and quantity of empirical research on environmental factors driving migration depend on increased collection of quantitative data (Bilsborrow and Henry 2012; Piguet 2010); adoption of sophisticated statistical modeling approaches (Kniveton, Schmidt-Verkerk, Smith, and Black 2008: 7); and greater collaboration between environmental and migration researchers (Kniveton, Schmidt-Verkerk, Smith, and Black 2008: 57; McLeman 2014). We agree, and hope to promote such interdisciplinary collaborations between environmental and population scientists. While human environment geographers and others have mapped linkages between ecological and social systems (e.g. Adger 2000; Anderies, Janssen, and Ostrom 2004), demographers have developed statistical tools that link contexts to individual and household outcomes (Entwisle 2007). As population scientists, we review knowledge of the data collection methods and statistical analyses used routinely by demographers to measure migration and its contextual-and individual-level drivers as our contribution toward this interdisciplinary effort.

This paper is organized as follows. First, we review the demographic approach to the study of migration and then explore survey and surveillance data and statistical methods used by demographers to study individual- and household-level migratory responses to environmental changes. Next, we discuss the demographic data and methods applied in four empirical investigations illustrating a variety of migration types and regression-based statistical methods. This collection of articles considers both rapid and slow onset environmental changes and their effects on temporary, permanent, internal, and international migration. Specifically, these studies examine (1) the relationship between rainfall in rural Burkina Faso and first out-migration to rural, urban, or international destinations for men 
and women; (2) return migration to New Orleans after Hurricane Katrina caused a complete evacuation and extensive damage to homes; (3) local and long-distance migration from rural households in Bangladesh following flooding and crop failures; (4) temporary and permanent out-migration from households in rural South Africa caused by variation in the availability of local natural resources. Finally, we discuss how the demographer's toolkit of measures, data, and methods can contribute to the science of environment-migration relationships.

\section{The demographer's toolkit for environment -migration research}

\subsection{Measuring migration}

Broadly, demography is the scientific study of human populations with primary focus on the three core processes underlying population dynamics: fertility, mortality, and migration. The combination of these fundamental dynamics determines the resulting size and distribution of human populations - key elements in understanding the demographic implications of contemporary climate change (Hugo 2011). To study individuals' entries (births and inmigration) and departures (deaths and out-migration) from specific populations, demographers use a wide variety of data collection and analytical methods (Preston, Heuveline, and Guillot 2001; Shryock and Seigel 1976). As opposed to other core demographic processes -- fertility and mortality -- migration lacks a biological component, making migratory events more difficult to measure. While births and deaths are registered routinely by hospitals and departments of health, changes of residence or border crossings are rarely recorded at the specific time of the event. Instead they are measured through ongoing data collection activities - censuses or administrative records - or with surveys (Bell, et al., 2014; Shryock and Seigel 1976). For the purposes of studying environmental factors associated with individual or household migrations, survey and surveillance approaches provide data that allow the timing of an environmental event or change to be associated with a migration. Census data is only collected at multi-year intervals and therefore more difficult to associate with the timing of a migration. Therefore, in the remainder of this review we focus on survey and surveillance data that measure household-or individual-level migratory behavior.

Conceptually, migration involves a change of usual residence (Lee 1966). There are both spatial and temporal dimensions to migration, as well as distinctions between migrant trips according to migrants' agency or volition (Fussell 2012; McLeman 2014). Most scholars define migration as either voluntary or involuntary, although most movements fall on a continuum between these two extremes. In practice, when movement involves some choice behavior, it may be treated as voluntary although migrants' choices may be precipitated by an unwelcome event or constrained by circumstances (Richmond 1993; Hugo 1996). In contrast, the cause of involuntary migration is well understood, for example, in the case of refugees fleeing their country with a well founded fear of persecution. The spatial dimension of migration is referenced by the type of boundary crossed, with the most common distinction between international and internal boundaries, or by characteristics of origin and destination, such as rural-to-urban or rural-to-rural moves. Although most migrants responding to environmental causes select destinations within their national boundaries, it is 
desirable to measure the full range of destinations (Bilsborrow, et al., 1997). Scholars describe the temporal dimension of migration using terms such as seasonal, temporary, recurrent, continuous, indefinite, and permanent (McLeman 2014). However, migrants may not know when (or whether) they will return or move on from their current location, so researchers may impose a temporal definition based on migrants' stated intentions, observed behavior, or the terms of their admission to a foreign country. The critical concern, voiced by many migration scholars, is to measure migration in a consistent manner, considering all of its dimensions, to increase comparability across data sources (Bell, et al., 2014; Center for Global Development 2009; Skeldon 2012).

Historically, migration theory and research tend to focus on internal labor migration, with a focus on working-age adults and men within a particular country (Sjaasted 1962; Todaro 1969). Scholars have shifted from this neo-classical economic view of migration to the New Economics of Labor Migration model which conceptualizes the household as the migration decision-making unit rather than an individual or head of household (Massey et al., 1998; Stark and Bloom 1985). Thus, researcher's choice of an individual or household as the unit of analysis reflects their theoretical model of migration and influences their findings, particularly the extent to which non-economic factors matter for migration outcomes. Such factors may include the number, age, gender, and labor force status of household residents, prior migration by household residents or relatives, and, especially for rural households, access to natural resources that provide livelihoods, food, water, fuel, or supplemental earnings (Ellis 1998). Household and contextual variables are essential for understanding how migration may be affected by livelihood diversification options.

To model the effect of contextual or household variables on individual outcomes, demographers often use hierarchical models, or more specifically, random effects models that account for the clustered nature of the data (e.g. Gray 2011; Yabiku, Glick, Wentz, Haas $\&$ Zhu 2009). These random effects models capture contextual effects; however, geographers have noted that geographic scale affects measurement of the phenomenon under study (Leyk et al., 2012). Specifically, while the available scale of demographic data may correspond to political boundaries or some other arbitrary boundary, e.g. census tracts, this scale may not correspond to the scale at which the phenomenon of interest operates, e.g. precipitation quantity or soil quality. Known as the modifiable areal unit problem, this problem potentially biases regression results by understating or overstating the effect of a spatial measure on a migratory outcome (Montello 2001). This important issue needs to be considered in the design of future demographic data collection efforts.

\subsection{Sources of Migration Data}

There are four commonly used sources of migration data: population registers, censuses, surveillance systems, and surveys. Each of these sources has strengths and weaknesses (Bell, et al., 2013: Table 5; Skeldon 2012). Only a few countries, mostly in Asia and Europe, have mandatory population registries that record residential movements and can thus be used to track migration directly. However, the reliability of registry data depends upon social acceptance of the system and country-specific registration rules. For the many countries that do not have registries, censuses and surveys are typical sources of migration data for the 
study of internal or international migration. Censuses have full population coverage and rich geographic detail, however, their temporal coverage is sparse and questions do not fully capture migration histories. In contrast, surveys better capture migration dynamics with detailed migration histories allowing the study of causes (and consequences) of individual and household-level migration. Indeed, most research examining migration dynamics relies on surveys. Therefore, in this section we focus on the availability, strengths, and weaknesses of surveys in particular.

Surveys are a flexible means of collecting detailed migration data, and can be inexpensive in comparison to other data collection methods (notably censuses). Survey researchers are concerned with establishing internal and external validity. Internal validity requires meeting at least three criteria: (1) the cause must temporally precede the effect; (2) there must be statistical correlation; and (3) the cause must be non-spurious, which means that it is a "true" cause and not simply a correlate of the outcome. External validity is established when the sampling strategy involves a random selection process, as well as a sufficiently high and unbiased response rate, to demonstrate that the sample represents the population. We review options for establishing each of these below (see Babbie 1986 for a full treatment).

Temporal order of the measures is built into the survey design. Survey researchers have three options: (1) cross-sectional survey design, which collects data from individuals or households only once; (2) multiple cross-sectional survey design, which involves repeated cross-sectional surveys of the same population but not the same individuals or households; or (3) longitudinal or panel survey design, which follows the same individuals or households over time. Retrospective survey questions that specify the timing of a migratory event are necessary in the first design, and are preferable in the others. The cross-sectional survey infers temporal order between environmental factors and a migratory response by asking retrospective and timing-specific questions. For example, if migration followed an environmental event such as a natural disaster, the first criterion for establishing causality (ordering) has been met. Multiple cross-sectional surveys that occur before and after an environmental change or event can better demonstrate causality by revealing shifts in population-level behavior. Still, longitudinal or panel surveys provide the best data for establishing causal sequence by examining the same analytical units across time and establishing the temporal order of an environmental event or change and a migration. The other two criteria for establishing causality - statistical association and non-spuriousness are addressed in the section on data analysis.

While longitudinal surveys more powerfully establish cause and effect as compared to single or multiple cross-sectional surveys, they are more difficult to administer for several reasons. First, panel samples are difficult to recruit because household members may not feel comfortable sharing identifying information with researchers for a relatively longer period of time. Therefore, confidentiality must be assured. Second, researchers must be able to maintain contact with household members if they migrate. Both of these challenges threaten a sample's external validity since individuals/households willing to be surveyed may be systematically different from those who refuse participation, as well as there being potential distinctions between those retained by the survey and those who migrate. The additional rounds of data collection and extra effort to locate all sampled households add to data 
collection costs. Thus, many researchers determine that the more cost-effective and practical cross-sectional research designs will suffice.

The sampling strategy, if successfully deployed, establishes external validity by producing a representative sample of the population. Such a probability-based sample, combined with valid and reliable measures of socio-economic and demographic characteristics and processes, allows researchers to make accurate generalizations. To obtain a representative sample, the researcher defines the geographic or social boundaries of the population to be studied and then determines whether there is a sampling frame-an exhaustive list of households or individuals - from which to draw a sample.

When a sampling frame is available researchers may use a simple random sampling design, in which every sampling unit has an equal chance of selection, or a stratified sampling design, in which the chances of selection are unequal but known. The latter may be preferable when the researcher is interested in the behaviors of a relatively small sub-group, such as migrants who may be unevenly distributed geographically. In the absence of a sampling frame, cluster sampling may be used in which researchers randomly select larger units, such as neighborhoods or villages, and then randomly select households or individuals within that subset of places. Weights are used in stratified and cluster sample designs to account for variations in selection probability. The number of sampling units surveyed determines the statistical power of the survey and sampling error. Furthermore, response rates must be adequately high to demonstrate that non-response bias is not a threat to external validity.

Sampling decisions in migration research are especially challenging since population mobility makes it difficult to find a complete sampling frame. For example, especially in the cases of international migration and temporary migration, random samples of origin communities will include households from which some or no members have out-migrated, but will miss households that have out-migrated altogether. To address this problem, researchers have undertaken bi-national migration surveys that sample households in the origin community and follow referrals to migrants in the principal destination communities (e.g. Massey 1987). To our knowledge there are four such projects: the Mexican Family Life Survey (Rubalcava and Teruel 2008), the Mexican Migration Project (Massey, Durand, and Malone 2001), the Latin American Migration Project, and the Migration between Africa and Europe Project (Beauchemin \& Gonzalez-Ferrer 2011). The problem of locating the highly mobile is not easily overcome. Households that move frequently or have moved recently are likely to be missing from data sources that serve as sampling frames, such as phone books and voting registries. Additionally, migrants may cluster in particular neighborhoods, so their numbers would not be accurately estimated by a random sampling of a geographic unit. The issue is further complicated in the case of migrants who actively avoid having their presence recorded. In such cases, non-probability samples are often used, but with the caveat that they are not necessarily representative, and therefore, the research results are not generalizable. Attention to these concerns when developing a sampling strategy is necessary to ensure high quality data. 
Demographic surveillance sites represent unique forms of censuses that resemble surveys in their more detailed and focused questions and their limited geographic coverage. There are over 30 such sites across Africa, Asia and the Americas, with core demographic data (births, deaths, and migrations) collected on a regular basis from an entire population. These sites produce knowledge about demographic and health issues in countries that often lack health information or vital registration systems (Baiden, Hodges and Binka 2006). As long as geographic identifiers are available for households, surveillance sites offer unique opportunities to combine demographic and geographic information and allow researchers to choose the appropriate scale for studying the effects of an environmental phenomenon on migration (Leyk et al., 2013).

A well-designed survey sample must be complemented with valid and reliable survey questions. To establish causes of migration, these questions should produce time-specific measures of migration. In cross-sectional data this is done by asking retrospective questions, such as "What month and year did you first leave your home to live in another place?" Yet such retrospective measures are subject to recall bias. Prospective studies which observe all households at several time points can more reliably measure migration by observing changes in household composition and asking about departures and additions. Measures collected in the baseline survey can be used to explain changes observed at the follow-up survey. Often, researchers duplicate questions used in other surveys in order to compare across contexts and increase the explanatory power of their research. As more researchers investigate environmental factors influencing migration, migration measures and data sources are likely to be improved and standardized to increase comparability across studies.

\subsection{Combining demographic survey data with environmental data}

Much existing environment-migration research relies on the timing of an environmental event, or environmental change, as a proxy measure of its impact. More nuanced and direct measures of environmental effects can be combined with demographic data, either through their measurement in the survey or census itself or by merging environmental and other contextual variables with demographic data (Bilsborrow and Henry 2012). These options broaden the potential set of explanations for migration by situating a household within a set of environmental, political, economic, and social arrangements. Furthermore, it closely operationalizes conceptual models which argue that environmental changes are channeled through macro- or contextual-level variables which affect households' migration decisions (e.g. Black et al., 2011).

High-quality and high resolution environmental datasets appropriate for this purpose have become increasingly available at the global scale, driven in large part by the increasing sophistication of satellite remote sensing and climate science. Publicly-available datasets include climate-related variables such as temperature and precipitation (e.g. Compo et al., 2011; National Climatic Data Center 2013), climate-linked vegetation indices (Pettorelli et al., 2005), and data reflecting the extent and severity of natural disasters (EMDAT 2013), though the latter lag in coverage and data quality. In many cases it is also desirable to collect respondents' own environmental experiences and/or perceptions. This approach builds on a large literature documenting individuals' detailed observations of their local environment 
(Hunter, Strife and Twine 2010; Huntington 2000; White and Hunter 2009). Collecting data on experiences and perceptions also allows the construction of household-level measures and permits the investigation of relationships between measured and perceived environmental shocks (Gray and Mueller 2012a). Data that forecasts climatic trends can also be associated with current population data to develop future migration scenarios (Curtis and Schneider 2011).

\subsection{Methods for Analyzing Combined Environmental and Population Data}

Multivariate regression models are often used to identify the association between environmental factors and migration while controlling for other variables relevant to migration. Here, we focus on individual- or household-level models of migration. However, aggregate migration flows between counties, states, or nations may also be modeled as a function of economic relationships in "gravity models" (Abel 2013; Kim and Cohen 2010), with examples of recent studies of environmental causes of migration flows at this scale including Marchiori et al. (2012), Curtis and Schneider (2011) and Curtis, Fussell, and DeWaard (in press). At the individual or household level, migration, our outcome variable, can be measured as an event, a count of migratory trips an individual has undertaken, or a count of migrants in a household. Factors associated with migration - potential causes - are the demographic, social, economic, political or environmental characteristics of individuals, households, and communities, many of which may change over time. Demographers have several approaches to modeling environment-migration relationships that take into account how migration is measured as well as temporal and spatial variation in explanatory factors.

2.3.1 Migration as an event or a count of trips or migrants-Hazard analysis also known as survival or event history analysis - models individuals' or households' duration in a "state". In our case, this is the state of being "at risk" of migrating, which ends when a migration occurs or the observation period ends. The most important quality of hazard analysis is that it accounts for "censored" cases for which no migration occurs by the end of the observed period. If these censored cases were treated as non-migrations, the estimated coefficients would be biased. Instead, unbiased estimates for each covariate are obtained since the units of analysis are periods of time. Each analytical unit - be they individuals or households - are represented in the dataset according to the period of "risk exposure" -- continuous time or a person/household-year or month, for example.

Researchers choose different types of hazard models depending on assumptions about migration timing, the distribution of the error term, and whether the event is measured in continuous or discrete time units. However, all hazard models are capable of measuring the effect of multiple independent variables, some of which may change over time, on an individual's risk of experiencing an event -- in our case, migration (Yamaguchi 1991). Three of the four articles reviewed in section 3 use hazard models, two with retrospective measures from cross-sectional surveys (Fussell, Sastry and VanLandingham 2010; Henry, Schoumaker, and Beauchemin 2004) and one with longitudinal panel data using prospective measures (Gray and Mueller 2012b).

As opposed to modeling migration's timing, counts of migrants or migratory trips demand a different modeling approach. Migration is a relatively rare event, with most people never 
migrating. However, individuals who do migrate are likely to migrate repeatedly and households with one migrant are likely to send additional migrants. Because such a variable is not normally distributed, it is more appropriate to model a count variable with a Poisson or negative binomial regression model rather than an ordinary least squares model. The Poisson model uses a natural logarithmic link to linearly produce count estimates. If the variance of the dependent variable is larger than its mean, a negative binomial regression is preferred (Hoffman 2004). An illustration of this modeling approach is provided by one of the articles reviewed section 3 (Hunter et al., 2013).

\subsubsection{More complex models of the effects of time and place on migration-}

Panel data and multi-level data also require more complex modeling than data measuring individuals or households at only one point in time. Longitudinal panel data involves multiple observations of the same subjects over time. Fixed effects models account for shared characteristics of observations within the same unit by holding constant the subjectspecific intercept while estimating the effects of time-varying variables measured at the same level. Within-subject dependence can also be addressed with a random effects model which estimates the effects of constant and time-varying independent variables on the dependent variable as well as a random intercept, which indicates how much of the variance in the dependent variable is due to time-invariant subject specific characteristics (RabeHesketh and Skrondal 2008). Hunter et al. (2013) use panel data to examine change in the number of migrants in a household.

Contextual variables are incorporated into models of migration behavior - whether a hazard model or a count model - by using nested multi-level models (Rabe-Hesketh and Skrondal 2008). Two of the four articles reviewed in section 3 use multi-level data to measure households clustered within villages. Households within the same village will have correlated error terms since they are exposed to a common set of conditions. This violates the regression assumption of independent errors, leading to artificially small error terms, and potentially to an incorrect conclusion that a relationship between an explanatory variable and the outcome is statistically significant. Henry et al. (2004) and Gray and Mueller (2012b) account for this by using Huber-White standard errors in their survival analyses. A more sophisticated approach used by Hunter et al. (2013), is multi-level modeling, which fixes the effects of the shared exposures of households within the same village, thereby controlling for unobserved heterogeneity while estimating the effect of household-level access to natural resources on the number of household migrants in the past year. These refined modeling approaches more precisely estimate the causal effect of an environmental event or change on the likelihood of migration. In section 3 we illustrate the demographic data and methods reviewed here with four case studies of environment-migration research, chosen to illustrate a variety of research settings, data, and methods.

\section{Case studies}

Research on environment-migration connections shows that the character of the environmental change (i.e., rapid- versus slow-onset) and the context in which the change occurs (i.e., rural or urban and level of national development) are associated with different kinds of migration behavior (i.e. seasonal, temporary, permanent, internal, or international). 
We selected four articles that reflect these differences and thereby illustrate the flexibility of demographic data and methods. They do so by employing a variety of sampling designs; distinct temporal designs for measuring change; and the range of statistical methods discussed in section 2.3. We summarize the characteristics of each article in Table 1.

\subsection{Rural Burkina Faso: Merging Longitudinal Data Sources}

Burkina Faso is one of poorest and least urbanized countries in world, and the nation's rural populations are heavily dependent on rain-fed agriculture and cattle ranching. While rainfall is scarce in the north and more plentiful in the south, the past 50 years have seen a declining rainfall trend. Combined with poor soil fertility, these rainfall declines mean both agriculture and ranching are livelihood strategies highly vulnerable to environmental variability and climate change. Henry, Schoumaker and Beauchamin (2004) investigate whether drought conditions produce temporary or permanent international migration or internal rural-tourban or rural-to-rural migration, either as a means of diversifying income or reducing the number of consumers in stressed origin areas.

To examine these connections between environmental conditions and migration, the authors merge data from three coordinated sources:

1. A nationally-representative retrospective survey collected individual life histories of migration and employment for 8,644 individuals aged 15-64 at time of survey. They define migrations as any trip lasting more than 3 months, although only first trips are modeled in the analysis.

2. Community-level data were collected in early 2002 from retrospective community surveys in 600 settlements. The community surveys were designed to be linked to the life history data, and therefore represent all villages of life history respondents, and a large sample of villages where they had lived in the past.

3. Measures of mean annual rainfall between 1960 and 1998 and the percent of "normal" rainfall over the 3 preceding years were extracted to measure persistent drought.

The authors deemed an individual's first migration to be a particularly significant life event and the move most likely to incorporate potential environmental determinants. Because variables were not available for all years, only the years 1970 through 1998 were included in the analyses. Event history methods were used for this multilevel longitudinal data, with separate models estimated for men and women. Binary logistic regression models estimated the probability of migration in general, while multinomial logistic regression models allowed for competing risks in which migration was disaggregated by destination (rural, urban or abroad) and by duration (short-term or long-term). The models use Huber-White standard errors to account for clustering of observations.

The results show that although there was no overall association between rainfall levels and trends and first migrations, the environment-migration association differs by destination and the duration of migration. Men and women from rural regions with less rainfall are particularly likely to engage in short- and long-term migrations and to choose rural destinations; however, men are more likely to undertake long-term moves in years following 
poor rainfall conditions, while women are less likely to do so. There is no evidence that rainfall is related to long-term migration to urban areas and it appears that long-term migration abroad is most likely for men and women from areas with more abundant rainfall. These findings indicate that these presumably low-cost moves between rural areas may be a way to cope with shortages, at least among those who have not previously migrated.

This Burkina Faso survey represents path-breaking data collection and use of detailed individual- and community-level data for modeling a migration-environment association. In related research, Henry and her colleagues (2003) find that land degradation and land availability at origin and more favorable environmental conditions at destination also "push" and "pull" migrants between provinces in Burkina Faso. However, these factors operate along with socio-economic factors, confirming the complexity of these environmentmigration associations.

\subsection{Hurricane Katrina and New Orleans: A retrospective survey of a representative sample}

Natural disasters may produce at least temporary, but possibly permanent, out-migration if residents are evacuated or displaced from homes and livelihoods. Hurricane Katrina struck New Orleans, Louisiana on August 29, 2005 and produced a catastrophic disaster when the protective levees failed and caused the below-sea-level city to flood. About 85 percent of residents fled in response to a mandatory evacuation order and all who remained in shelters, homes, and hospitals, except police, fire fighters and search and rescue teams, departed in the following week. The flood waters were removed nearly a month later, and only then were neighborhoods reopened for occupancy as they were deemed safe.

Fussell, Sastry and VanLandingham (2010) present one of the few demographic studies todate of displacement and return migration following a natural disaster. The environmentmigration relationship in this case is one in which some residents - specifically AfricanAmericans and lower-educated residents - were more vulnerable to the disaster's effects, resulting in lower and slower rates of return migration.

To investigate the unequal rates of return among residents by race and socio-economic status, Fussell et al. (2010) draw on a cross-sectional retrospective survey, the Displaced New Orleans Residents Pilot Study (DNORPS; Sastry 2009). The survey's sampling strategy involved identifying a complete roster of addresses from before the date of the disaster, and then sampling dwellings stratified by level of flooding. In the fall of 2006, the survey researchers used a variety of techniques to track pre-Katrina residents of these dwellings to their post-Katrina locations for interview. The difficulty of finding residents is reflected in the fact that only about two-thirds of households could be located and, of these, only $80 \%$ were successfully contacted. Together with a small number of refusals, this led to an overall response rate of 51\% and a completed sample size of 147 households and 291 adults. Weights are used to take into account differences in likelihood of response as well as flood-level stratification (more flooded areas being less likely to be represented in the survey). DNORPS was an important proof of concept, showing that it is possible to trace displaced residents. For a description of a similar effort in the context of the Indian Ocean Tsunami, see Gray et al. (2014). 
In the study, return migration to New Orleans is defined as ever residing in the metropolitan area following the hurricane. Environmental exposure is measured with a self-report of housing damage due to Hurricane Katrina. The rate of return was significantly different by race and educational attainment. By the time of the survey only $51 \%$ of blacks had returned relative to $71 \%$ of the non-black population and $52 \%$ of those with less than a college degree had returned relative to $71 \%$ of those with a college degree or more. The authors then use a discrete-time hazard model to incorporate co-variates into the analysis of return migration. The results confirm that non-black residents and residents with at least a college degree returned more quickly, however, these differences were not statistically significant once the level of housing damage was included in the model. Evidently, the slow return of these subgroups is associated with housing damage, consistent with the observed spatial pattern of damage in majority black and lower-income neighborhoods. Thus, while the descriptive results confirm that the black and low education groups within the population are more vulnerable to long-term displacement, the underlying cause was disproportionate exposure of neighborhoods to flooding and housing damage.

The event history analysis of cross-sectional retrospective data of a sample of disasteraffected residents allows Fussell et al. (2010) to identify a causal mechanism behind racialand class-based differences in the rate of return migration. Although there are difficulties in collecting a representative sample in a post-disaster context, this pilot study demonstrates its feasibility. Nevertheless, the data are limited by the small sample size and possible recall error in measurement.

\subsection{Rural Bangladesh: Innovative Use of Existing Panel Data}

Gray and Mueller (2012b) challenge the "conventional narrative" often advanced in public and policy dialogue that the poor and vulnerable are most likely to migrate in the face of environmental challenges. For their analyses, the authors use longitudinal survey data from the Chronic Poverty and Long Term Impact Study, collected by the International Food Policy Research Institute (IFPRI). The data span 1994-2010 and represent 1,680 households in 102 communities within 14 districts of rural Bangladesh. Although not representative, the survey's geographic coverage encompasses much of the country.

In this setting, households depend on rice production although they also experience high levels of food insecurity due to the unpredictability of livelihoods. As examples, the region experienced two large-scale floods in 1998 and 2004, as well as a series of other natural disasters such as coastal storms and crop failures due to rainfall deficits. These are measured in the survey by household reports of annual flood-related damages or income losses. The researchers also collected information on non-flood related crop failures which are primarily due to rainfall deficits. As a check on respondent reports, rainfall measures were also derived from a satellite data source.

Gray and Mueller estimate discrete time event history models, with person-years representing the analytical unit. Overall, 4,646 individuals were "at risk" of migration, defined by age and relationship to the household head. A total of 32,229 person-years of exposure are represented within the dataset. Both dichotomous $(0=$ non-migration; $1=$ migration $)$ and multinomial logistic $(0=$ no migration; $1=$ local, $2=$ long distance $)$ 
regression models are used, making use of baseline as well as time-varying individual, household, village and sub-district-level predictors. Standard errors are adjusted for sample clustering at the village level. The authors fit five different model specifications that include fixed effects for the subdistrict and year to account for any baseline differences as well as shifts in national context.

They find that, contrary to the hypothesis that rapid onset disasters produce out-migration, flooding at the subdistrict level has no effect on out-migration. Only in subdistricts with moderate levels of flooding was there an increased likelihood of migration among women and the poor. Surprisingly, crop failures, a slower onset disaster, increase overall, short- and long-distance out-migration at the subdistrict level. However, at the household level, crop failure's effect becomes negative - suggesting direct exposure to this form of environmental shock reduces household mobility and indirect exposure increases it. Furthermore, in subdistricts with a higher percentage of crop failures, households with higher per capita expenditures are more likely to send migrants and women are more likely to migrate.

Through this carefully crafted series of event history models and the comparison of two types of disasters - floods and droughts - Gray and Mueller (2012b) conclude that exposure to disasters does not have consistently positive effects on migration, and furthermore, that disasters can actually reduce mobility through resource constraints. Although Gray and Mueller (2012b) are limited to examining permanent moves rather than temporary ones, their analytic approach addresses a priori many of the typical questions that arise within quantitative environment-migration studies (e.g. long vs. short distance mobility, gender distinctions, household vs. larger geographic scale effects). In particular, their use of both contextual and household-level measures of exposure to environmental shocks provides new insights into how natural disasters affect rural households in the developing world.

\subsection{Rural South Africa: Tapping into the Spatial Potential of Demographic Surveillance}

Variability in local natural resources - fuel wood, construction material, plant fiber, edible herbs and medicinal plants - caused by drought and rainfall may affect the likelihood of outmigration by resource-dependent households through a variety of pathways. A lack of local natural resources may negatively impact a household's food security, for example, or constrain a household's ability to generate income from resource-based market activities (e.g. making baskets or mats). Such shifts may increase the need to generate household remittances through sending a temporary migrant for employment elsewhere. However, particularly disadvantaged households may be unable to engage in migration as movement entails costs (as seen by the above example in Bangladesh). Yet this particular form of environment-migration association is difficult to observe because of the challenges in matching spatially dispersed household surveys with very local environmental conditions. Surveillance data, in which every household within a defined geography is observed at a regular time interval, occurs at a geographic scale fine enough to relate environmental variation to household behavior (Leyk, et al., 2012).

Hunter et al. (2013) use the Agincourt Health and Demographic Surveillance System (AHDSS) data to analyze the effect of natural resource availability and variability on rural out-migration from a former black South African "homeland" in the northeastern part of the 
country close to the Mozambique border. They use data from the year 2007, and migrants are based on a count of the number of temporary and permanent adult (age 15 and older) out-migrants during the previous 12 months. Temporary migrants have spent more than six months of the last year somewhere else and are most often labor migrants. Permanent migrants are discerned from questions about members who are no longer listed.

The authors merge household surveillance data with satellite images for the years 20052007. Vegetation varies across the study site both temporally and spatially according to rainfall, land productivity, and harvesting pressures. As such not all households have equal access to proximate natural resources at any given time. To measure variation in resource availability, the authors use the satellite imagery to calculate the normalized difference vegetation index (NDVI), a widely used measure of vegetation cover. Buffers of 2,000meters were created around each village, but including only communal landscapes, based on understanding of local harvesting patterns. Finally, for each village buffer, natural resource measures reflect the mean NDVI value, 2005-2007, in addition to the slope of values across the three time points as an indicator of short-term change (Foody et al., 2001; Wang et al., 2004).

To appropriately model migration from households within villages, the authors use a multilevel model, allowing the intercept and slope to vary across villages, and adjusting for clustering of observations, different sample sizes for the level-1 and level-2 units, and heteroskedastic error terms. They use a Poisson transformation of the count of the number of temporary or permanent migrants in 2006-2007. Results reveal a strong positive relationship between the village level measure of natural resources and temporary out-migration, but not permanent out-migration. Furthermore, greater access to natural resources is more influential for households with higher levels of education, suggesting that households with lower levels of education are constrained from diversifying their income sources. However, when natural resource availability increased overall, less advantaged households were more likely to out-migrate temporarily. Altogether, this suggests that natural resources, a livelihood asset, fuel further asset diversification by facilitating temporary labor migration. The finding that "natural capital" may provide resources necessary for additional livelihood diversification through migration echoes the findings of Gray and Mueller (2012b).

This research significantly advances the migration-environment literature through the use of novel data sources, a sophisticated analytical approach, and a focus on temporary migration -- an important form of livelihood migration that is often not separately examined. In other research (Leyk, et al., 2012), this team has shown that smaller scale spatial models fit the data best and produce more robust results.

\section{Discussion and conclusion}

While there is wide consensus that climate change will produce human migration, many unanswered questions about this relationship could be addressed by combining demographic data and methods with environmental measures. Examples of such questions are: Which types of environmental events or changes will be most important in producing migratory responses? Which types of migratory responses will be associated with specific types of 
environmental events or changes? Which of the social, political, economic, or demographic structures that channel environmental drivers of migration will be most influential? Which groups within a population will be most likely to migrate? What are the differences between groups in their likely destinations? Which groups will be immobile? Empirical investigations that answer these questions will allow for better prediction of future environment-migration scenarios.

The demographic data and methods reviewed here demonstrate multiple research approaches for examining relationships between environmental changes and events and migration. Each of the four articles reviewed in section 3 show that while migration is an adaptive response to changing environmental conditions, those conditions also tend to limit migration in one way or another (Black, et al., 2013). This is evident from the finding that in rural Burkina Faso low rainfall was associated with increased migration to other rural destinations, but not to urban areas or foreign destinations. Households in rural Bangladesh experiencing crop failure and those in rural South Africa with reduced natural capital, respectively, were less likely to migrate or send as many migrants. Likewise, less advantaged displaced New Orleanians were less likely to return to their pre-disaster homes in large part due to the greater average level of housing damage these groups experienced. Migration was more likely to occur among those who either benefited from environmental change (residents from areas experiencing more rain in Burkina Faso and households experiencing more "greenness" in South Africa) or were indirectly affected (residents of flooded subdistricts whose crops were not affected in Bangladesh) or relatively less affected (New Orleans residents with less damaged homes). While these four examples are hardly sufficient for making generalizations, they provide examples of the kinds of studies appropriate for a meta-analysis focused on regularities in environment-migration interactions. Notably, their findings go against the conventional narrative that disasters produce migration of the most harmed. To date, there are too few empirical studies with comparable measures of environmental exposures, socio-ecological contexts, and migration responses to support a meta-analysis that would confirm this generalization.

The challenge of comparing case studies of environment-migration relationships is exemplified here. All four cases examine unique environmental events or changes. The mechanisms through which these environmental exposures produce migration are also distinct, demonstrated most clearly by Gray and Mueller's (2012b) finding that crop failure produce out-migration while flooding did not, at least at the subdistrict level. Just as there are a diverse range of environmental exposures, there is diversity in migration response and its measurement (e.g. first migration versus later migrations; out-migration, in-migration, or return-migration; short-distance, long-distance, or foreign migration; temporary versus permanent migration; household versus individual migration). To successfully compare case studies, greater comparability in measurement of both environmental exposures and migration responses is necessary.

However, some patterns emerge in the existing research. Most notably, and as evidenced in our case studies, migration responses to slow-onset environmental changes and rapid-onset environmental events differ (Kniveton et al., 2008; McLeman and Hunter 2010; Tacoli 2009). Migratory responses to slow-onset changes, such as drought, desertification, and land 
degradation, tend to be short-distance and temporary and selective on socio-demographic characteristics. In short, they are more akin to labor migration as a means of livelihood diversification (Findley 2011). In contrast, rapid-onset weather events, such as hurricanes, typhoons, and tornados, produce crisis-driven migration, but only when affected residents are unable to shelter in place and quickly recover their homes and livelihoods (Peacock, Dash, and Zhang 2007; Paul 2005). Such migrations typically involve evacuations or displacements of entire households, many of which later return to the affected area. To make even firmer generalizations, we need statistical data with comparable measures of environmental exposures and migration outcomes that come from a wider range of contexts (Brown 2008; Jäger et al., 2007). To date, research sites are concentrated in the global South, especially sub-Saharan Africa, and tend to focus on rural regions experiencing gradual changes in ecosystem services (Kniveton et al., 2008).

To meet the need for wider global coverage and comparable data, existing census and survey data could be augmented with standardized migration questions (Bell et al., 2014; Bilsborrow and Henry 2012; Center for Global Development 2009). However, a more ambitious goal is a global survey of environment-migration processes. In the past, demographic data and analytic methods have been marshaled to meet pressing needs for knowledge of global problems. The World Fertility Survey, and its successor the Demographic and Health Survey, provides a good example. Between 1974 and 1983 the International Statistical Institute, funded by the U.S. Agency for International Development and other sponsors, carried out fertility surveys in 61 countries, involving interviews with nearly a quarter of a million women of reproductive age. The findings of these surveys lead investigators to conclude that socioeconomic development, especially the education of women, combined with access to family planning, expedites the process of fertility decline (Cleland and Scott 1987). These findings were instrumental in creating and prioritizing policies aimed at lowering fertility and subsequent population growth. Other international surveys have addressed various topics such as living standards (Living Standards Measurement Survey; http://www.worldbank.org/), public opinion (International Social Survey Program; http://www.issp.org/), secondary education (International Student Assessment; http://nces.ed.gov/surveys/pisa/), and tobacco use (Global Tobacco Surveillance System; http://www.cdc.gov/Tobacco/global/gtss) (Thompson 2008). All provide examples of ambitious yet feasible global statistical investigations of high-priority topics and all implement comparable measures of hypothesized causes and effects while varying contexts.

We concur with Kniveton and his colleagues (2008: 57) who state, "Only through the interdisciplinary study of the relationship of climate with migration involving detailed data collection and conceptual and numerical model development can a picture be developed of the potential changes to migration in the future due to the impact of climate change." A global survey of environment and migration is a direct response to the calls for more data and research that echo throughout the literature (Brown 2008; Jäger et al., 2007; Kniveton et al., 2008; McLeman 2014; Hayes and Adamo 2013). By assessing existing sources of population and environmental data and exploring their potential for new research, we can go far toward advancing scientific knowledge of environment-migration relationships and their implications for the future. 


\section{Acknowledgments}

This paper emerged from conversations at a workshop on "Migration, Urbanization, and Climate Change" at the Institute of Behavioral Science, University of Colorado Boulder (USA). The workshop was supported by the National Center for Atmospheric Research (NCAR) Integrated Science Program (ISP) as well as the University of Colorado Population Center. The work has also benefited from the NICHD-funded University of Colorado Population Center (grant R21 HD51146) for research, administrative, and computing support. The participation of C. Gray was also supported by NICHD (HD061752). Fussell's participation was supported by a sabbatical from Washington State University and a visiting faculty position at Tulane University's School of Public Health and Tropical Medicine.

\section{References}

Abel GJ. Estimating global migration flow tables using place of birth data. Demographic Research. 2013; 28:505-546.10.4054/DemRes.2013.28.18

Adger NW. Social and ecological resilience: are they related? Progress in Human Geography. 2000; 24(3):347-364.10.4337/9781847205223.00012

Anderies JM, Janssen MA, Ostrom E. A framework to analyze the robustness of social-ecological systems from an institutional perspective. Ecology and Society. 2004; 9(1):18. URL: http:// www.ecologyandsociety.org/vol9/iss1/art18/.

Babbie, E. The Practice of Social Research. 4. Belmont, CA: Wadsworth Publishing; 1986.

Baiden F, Hodgson A, Binka FN. Demographic Surveillance Sites and Emerging Challenges in International Health. Bulletin of the World Health Organization. 2006; 84(3):161-256. In: http:// www.who.int/bulletin/volumes/84/3/editorial20306html/en/.

Beauchemin C, Gonzalez-Ferrer A. Sampling international migrants with origin-based snowballing method: New evidence on biases and limitations. Demographic Research. 2011; 25(3):103134.10.4054/DemRes.2011.25.3

Bell M, Charles-Edwards E, Kupiszewska D, Kupiszewski M, Stillwell J, Zhu Y. Internal migration data around the world: Assessing contemporary practice. Population, Space and Place. 2014 on-line. 10.1002/psp. 1848

Bilsborrow RE, Henry SJF. The use of survey data to study migration-environment relationships in developing countries: Alternative approaches to data collection. 2012; 34:113-141.10.1007/ s11111-012-0177-1

Bilsborrow, RE.; Hugo, G.; Oberai, AS.; Zlotnik, H. International Migration Statistics: Guidelines for Improving Data Collection Systems. International Labour Organization; Geneva: 1997.

Black R, Arnell N, Dercon S. Migration and Global Environmental Change -Review of Drivers of Migration. 2011; 21(Supplement 1):S1-S130.10.1016/j.gloenvcha.2011.10.005

Black R, Adger WN, Arnell NW, Dercon S, Geddes A, Thomas DSG. The effect of environmental change on human migration. Global Environmental Change. 2011; 21S:S3-S11.10.1016/ j.gloenvcha.2011.10.001

Black R, Arnell NW, Adger WN, Thomas D, Geddes A. Migration, immobility and displacement outcomes following extreme events. Environmental Science \& Policy. 2013; 27S:S32S34.10.1016/j.envsci.2012.09.001

Brown O. The numbers game. Forced Migration Review. 2008; 31:8-9.

Cleland, J.; Scott, C., editors. The World Fertility Survey: An Assessment. Oxford: Oxford University Press; 1987.

Center for Global Development. Report of the Commission on International Migration Data for Development Research and Policy. Washington, DC: Center for Global Development; 2009. Migrants count: Five steps toward better migration data. http://www.cgdev.org/publication/ migrants-count-five-steps-toward-better-migration-data [Accessed May 21, 2014]

Compo G, Whitaker J, Sardeshmukh P, Matsui N, Allan R, Yin X, Gleason B, Vose R, Rutledge G, Bessemoulin P, Bronnimann S, Brunet M, Crouthamel R, Grant A, Groisman P, Jones P, Kruk M, Kruger A, Marshall G, Mauger M, Mok H, Nordli Ø, Ross T, Trigo R, Wang X, Woodruff S, Worley S. The twentieth century reanalysis project. Quarterly Journal of the Royal Meteorological Society. 2011; 137:1-28.10.1002/qj.776 
Curtis KJ, Schneider A. Understanding the demographic implications of climate change: estimates of localized population predictions under future scenarios of sea-level rise. Population and Environment. 2011; 33(1):28-54.10.1007/s11111-011-0136-2

Curtis KJ, Fussell E, DeWaard J. Recovery migration after Hurricanes Katrina and Rita: Spatial concentration and intensification in the migration system. Demography. In press.

Ellis F. Household strategies and rural livelihood diversification. The Journal of Development Studies. 1998; 35(1):1-38.10.1080/00220389808422553

EMDAT (Emergency Events Database). The OFDA/CRED international disaster database. Université Catholique de Louvain; Brussels, Belgium: 2012. www.emdat.be

Entwisle B. Putting people into place. Demography. 2007; 44(4):687-703.10.1353/dem.2007.0045 [PubMed: 18232206]

Findlay AM. Migrant destinations in an era of environmental change. Global Environmental Change. 2011; 21S:S50-S58.10.1016/j.gloenvcha.2011.09.004

Foody GM, Cutler ME, McMorrow J, Pelz D, Tangki H, Boyd DS, Douglas I. Mapping the biomass of Bornean tropical rain forest from remotely sensed data. Global Ecology and Biogeography. 2001; 10(4):379-387.10.1046/j.1466-822X.2001.00248.x

Fussell E, Sastry N, VanLandingham M. Race, socioeconomic status, and return migration to New Orleans after Hurricane Katrina. Population and Environment. 2010; 31(1-3):20-42.10.1007/ s11111-009-0092-2 [PubMed: 20440381]

Fussell, E. Space, time, and volition: Dimensions of migration theory. In: Rosenblum, MR.; Tichenor, DJ., editors. The Oxford Handbook of the Politics of International Migration. Oxford University Press; New York: 2012.

Gray C, Frankenberg E, Gillepsie T, Sumantri C, Thomas D. Studying displacement after a disaster using large scale survey methods: Sumatra after the 2004 tsunami. Annals of the Association of American Geographers. 2014; 104(3):594-612.10.1080/00045608.2014.892351 [PubMed: 24839300]

Gray CL, Bilsborrow R. Environmental influences on out-migration in rural Ecuador. Demography. 201310.1007/s13524-012-0192-y

Gray CL, Mueller V. Drought and population mobility in rural Ethiopia. World Development. 2012a; 40(1):134-145.10.1016/j.worlddev.2011.05.023 [PubMed: 22523447]

Gray CL, Mueller V. Natural disasters and population mobility in Bangladesh. Proceedings of the National Academy of Science. Proceedings of the National Academy of Sciences. 2012b; 109(16): 6000-6005.10.1073/pnas.1115944109

Gray CL. Soil quality and human migration in Kenya and Uganda. Global Environmental Change. 2011; 21:421-430.10.1016/j.gloenvcha.2011.02.004 [PubMed: 22016577]

Hayes A, Adamo S. Introduction: Understanding the Links between Population Dynamics and Climate Change. Population and Environment. 201310.1007/s11111-014-0208-1

Henry S, Boyle P, Lambin EF. Modeling inter-provincial migration in Burkina Faso, West Africa: the role of socio-demographic and environmental factors. Applied Geography. 2003; 23:115-136.

Henry S, Schoumaker B, Beauchemin C. The Impact of Rainfall on the First Out-Migration: A MultiLevel Event History Analysis in Burkina Faso. Population and Environment. 2004; 25(5):423460.

Hoffman, JP. Generalized linear models: An applied approach. New York: Pearson Education; 2004.

Hugo G. Environmental concerns and international migration. International Migration Review. 1996; 30(1):105-131. [PubMed: 12291410]

Hugo G. Future demographic change and its interactions with migration and climate change. Global Environmental Change. 2011; 21S:S21-S33.10.1016/j.gloenvcha.2011.09.008

Hunter LM, Leyk S, Nawrotzki R, MacLaurin G, Twine W, Collinson M, Erasmus B. Rural Outmigration, Natural Capital, and Livelihoods in Rural South Africa. Population, Space and Place. 201310.1002/psp.1776

Hunter LM, Strife S, Twine W. Environmental Perceptions of Rural South African Residents: The Complex Nature of a Post-Material Concern. Society and Natural Resources. 2010; 23(6):525541. [PubMed: 20514147] 
Huntington H. Using Traditional Ecological Knowledge In Science: Methods And Applications. Ecological Applications. 2000; 10:1270-1274.10.2307/2641282

Intergovernmental Panel on Climate Change. Core Writing Team. Climate Change 2007: Synthesis Report. In: Pachauri, RK.; Reisinger, A., editors. Contribution of Working Groups I, II and III to the Fourth Assessment Report of the Intergovernmental Panel on Climate Change. IPCC; Geneva, Switzerland: 2007. p. 104

Jäger, J.; Frühmann, J.; Grünberger, S.; Vag, A. [Accessed 4 October 2012] EACH-FOR: Environmental Change and Forced Migration Scenarios: Synthesis Report. 2009. at: http:// www.each-for.eu

Kim K, Cohen JE. Determinants of international migration flows to and from industrialized countries: A panel data approach beyond gravity. International Migration Review. 2010; 44(4):899_ 932.10.1111/j.1747-7379.2010.00830.x

Kniveton, D.; Schmidt-Verkerk, K.; Smith, C.; Black, R. [Accessed December 17, 2013] Climate Change and Migration: Improving Methodologies to Estimate Flows. International Organization for Migration. 2008. at: http://www.iom.int

Lee ES. A theory of migration. Demography. 1966; 3(1):47-57.

Leyk S, Maclaurin GJ, Hunter LM, Nawrotzki R, Twine W, Collinson Mark, Erasmus Barend. Spatially and temporally varying associations between outmigration and natural resource availability in resource-dependent rural communities: A modeling framework. Applied Geography. 2012; 34:559-568.10.1016/j.apgeog.2012.02.009 [PubMed: 23008525]

Marchiori L, Maystadt J, Schumaker I. The impact of weather anomalies on migration in Sub-Saharan Africa. Journal of Environmental Economics and Management. 2012; 63(3):355-374.10.1007/ s00148-009-0274-3

Massey DS. The ethnosurvey in theory and practice. International Migration Review. 1987; 21(4): 1498-1522. [PubMed: 12280921]

Massey, DS.; Arango, J.; Hugo, G.; Kouaouci, A.; Pellegrino, A.; Taylor, JE. Worlds in Motion: Understanding International Migration at the End of the Millennium. Oxford, UK: Clarendon Press; 1998.

Massey, DS.; Durand, J.; Malone, NJ. Beyond Smoke and Mirrors: Mexican Immigration in an Era of Economic Integration. New York: Russell Sage Foundation; 2002.

McLeman R, Smit B. Migration as an adaptation to climate change. Climatic Change. 2006; 76:3153.10.1007/s10584-005-9000-7

McLeman R, Hunter LM. Migration in the context of vulnerability and adaptation to climate change: insights from analogues. WIREs Climate Change. 2010; 1:450-461.10.1002/wcc.51

McLeman, R. Climate and Human Migration: Past Experiences, Future Challenges. New York: Cambridge University Press; 2014.

Montello, DR. Scale in geography. In: Smelser, NJ.; Baltes, PB., editors. International Encyclopedia of the Social \& Behaviorial Sciences. Oxford: Pergamon; 2001. p. 13501-13504.

National Climatic Data Center. 2013. http://www.ncdc.noaa.gov/

Paul MK. Evidence against disaster-induced migration: the 2004 tornado in north-central Bangladesh. Disasters. 2005; 29(4):370-385. [PubMed: 16277646]

Peacock, WG.; Dash, N.; Zhang, Y. Sheltering and housing recovery following disaster. In: Rodríguez, H.; Quarantelli, EL.; Dynes, RR., editors. Handbook of Disaster Research. Springer; NY NY: 2007. p. 258-274.

Pettorelli N, Vik JO, Mysterud A, Gaillard JM, Tucker CJ, Stenseth NC. Using the satellite-derived NDVI to assess ecological responses to environmental change. Trends in Ecology \& Evolution. 2005; 20(9):503-510. [PubMed: 16701427]

Piguet E. Linking climate change, environmental degradation, and migration: a methodological overview. WIREs Climate Change. 2010; 1:517-524.10.1002/wcc.54

Piguet, E.; Pécoud, A.; de Guchteneire, P. Working Paper N 79. University of Oxford; 2010. Migration and Climate Change: An Overview, Centre on Migration, Policy and Society. Accessed: http:// www.compas.ox.ac.uk/publications/working-papers/wp-10-79

Preston, SH.; Heuveline, P.; Guillot, M. Demography: Measuring and Modeling Population Processes. Blackwell Publishers Ltd; Oxford UK: 2001. 
Rabe-Hesketh, S.; Skrondal, A. Multilevel and Longitudinal Modeling Using Stata. 2. College Station, Texas: Stata Press; 2008.

Richmond AH. Reactive migration: Sociological perspectives on refugee movements. Journal of Refugee Studies. 1993; 6(1):7-24.

Rubalcava, Luis; Teruel, Graciela. [Accessed May 23, 2014] User's Guide for the Mexican Family Life Survey Second Wave. 2008. http://www.ennvih-mxfls.org/

Sastry N. Tracing the effects of Hurricane Katrina on the population of New Orleans: The Displaced New Orleans Residents Pilot Study. Sociological Methods and Research. 2009; 38(1):171196.10.1177/1086026609347183 [PubMed: 20161061]

Shryock, HS.; Siegel, JS. The Methods and Materials of Demography. Academic Press, Inc; San Diego, California: 1976.

Sjaastad LA. The costs and returns of human migration. The Journal of Political Economy. 1962; 70(5):80-93.

Skeldon, R. Migration and its measurement: Towards a more robust map of bilateral flows. In: VargasSilva, Carlos, editor. Handbook of Research Methods in Migration. Northampton, MA: Edward Elgar; 2012. p. 229-248.

Stark O, Bloom DE. The new economics of labor migration. The American Economic Review. 1985; 75(2):173-178.

Tacoli C. Crisis or adaptation? Migration and climate change in a context of high mobility. Environment \& Urbanization. 2009; 21(2):513-525.10.1177/0956247809342182

Thompson ME. International surveys: Motives and methodologies. Survey Methodology. 2008; 34(2): $131-141$.

Todaro MP. A model of labor migration and urban unemployment in less developed countries. The American Economic Review. 1969; 59(1):138-148.

Wang J, Rich PM, Price KP, Kettle WD. Relations between NDVI and tree productivity in the central Great Plains. International Journal of Remote Sensing. 2004; 25(16):3127-3138.

Warner K. Environmental change and migration: Methodological considerations from ground-breaking global survey. Population \& Environment. 2011; 33:3-27.10.1007/s11111-011-0150-4

White MJ, Hunter LM. Public Perception of Environmental Issues in a Less Developed Setting: Environmental Concern in Ghana. Social Science Quarterly. 2009; 90(4):960-982. [PubMed: 22639472]

Yabiku ST, Glick JE, Wentz EA, Haas SA, Zhu L. Migration, health, and environment in the desert southwest. Population \& Environment. 2009; 30:131-158.10.1007/s11111-009-0082-4

Yamaguchi K. Event History Analysis. Applied Social Research Methods Series. 1991; 28:181. 


\section{Highlights}

- Reviews demographic data and methods appropriate for studying environmentmigration associations.

- Summarizes four examples of environment-migration research using different demographic data and methods.

- Such demographic data and methods can identify patterns of environmentmigration associations across multiple contexts.

- Identifying regularities in environment-migration associations will facilitate development of future migration scenarios. 


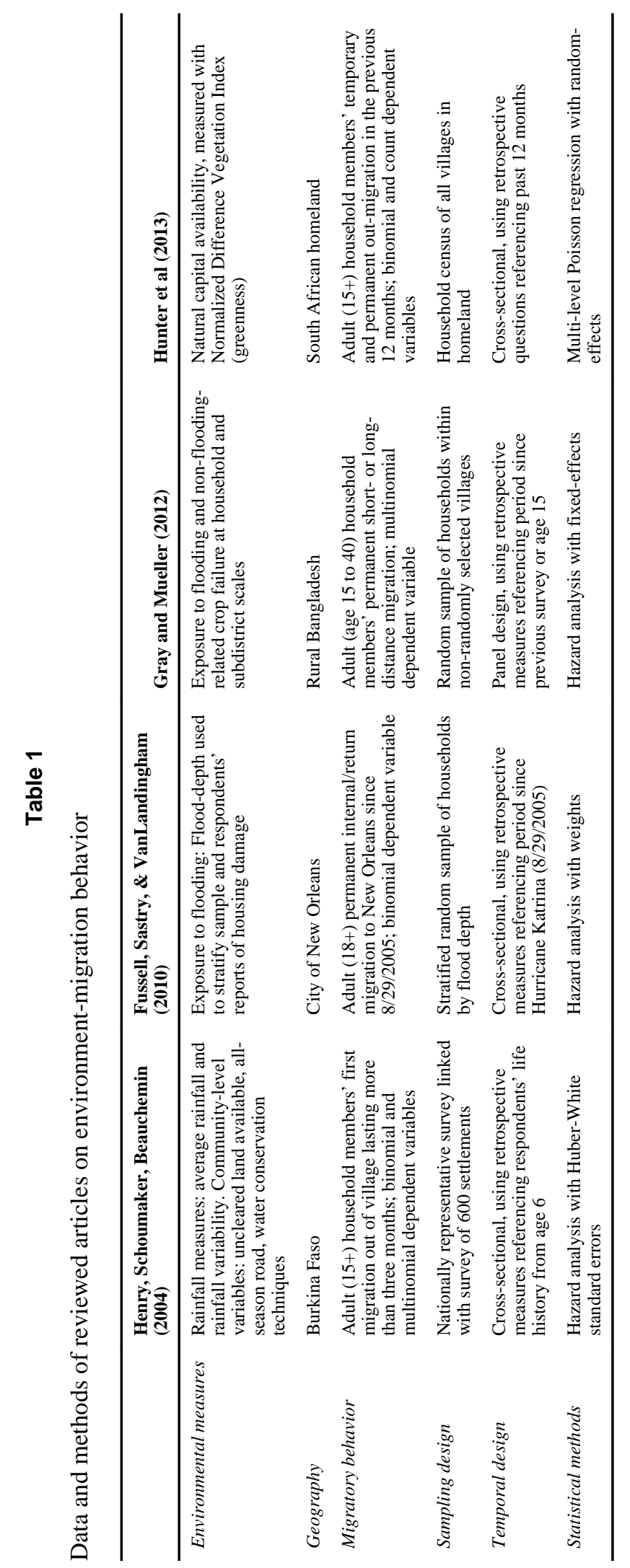

Glob Environ Change. Author manuscript; available in PMC 2015 September 01. 